\title{
TRACING HIGHLY ADAPTED STABLE YIELDING BREAD WHEAT (TRITICUM AESTIVUM L.) GENOTYPES FOR GREATLY VARIABLE SOUTH-EASTERN TURKEY
}

\author{
AKTAȘ, H. \\ Mardin Artuklu University Vocational School of Klzıltepe, Mardin, Turkey \\ E-mail: h_aktas47@hotmail.com \\ Phone: +904822152503 \\ (Received $14^{\text {th }}$ May 2016; accepted $22^{\text {nd }}$ Jul 2016)
}

\begin{abstract}
Wheat (Triticum aestivum L.) is the most widely adapted and cultivated cereal grain in the world. In 2013 cropping season, wheat was harvested on 1.3, 7.8, and 214 million ha in south-eastern Turkey, Turkey and World, respectively. Breeding programs in the Turkey have achieved tremendous gains in grain yield over past two decades. However, yield fluctuated over the years due to change in environmental conditions and genotype by environment interactions. Therefore, this study was conducted with overall objectives to identify high yielding and stable candidate genotypes for release in southeastern Turkey. A total of 25 genotypes with 20 advanced experimental lines and five check cultivars were planted at 10 locations in south-eastern Turkey in 2010-11 cropping season. Grain yield stability was determined using Eberhart and Russel, AMMI and GGE -biplot methods. Based on these results G1, G12, G13 and G19 were identified as the potential candidate genotypes for release. GGE-biplot classified south-eastern Turkey into two mega-environments. AMMI and GGE biplot explained 86.49\% and $86.43 \%$ of the total variation for grain yield, respectively. These result suggested that all three methods were equally efficient in determining the stability of the genotype. However, the GGE biplot methodology is more preferred than AMMI and Eberhart and Russel because it facilitates clearly visualize which-won-where pattern and the discriminating ability of environments.
\end{abstract}

Keywords: multivariate analysis, biplot, grain yield, stability, wheat

\section{Introduction}

Wheat (Triticum aestivum L.) accounts for more than a quarter of total world cereal production and provide calories for more than 1.5 billion people (Ekboir, 2002). Wheat is grown in different environmental conditions, predominantly under rainfed conditions in southeastern Turkey. Different classes of wheat encompassing spring, winter and facultative wheat are grown across 1.3 million ha in southeastern region of Turkey. Environmental differences, i.e., in precipitation, soil productivity, abiotic and biotic stresses and altitude within and across agroclimatic regions resulted in limited productivity and adaptability of currently available wheat varieties (Aktaş et al., 2010; Kilıç et al., 2010). Therefore, breeding for grain yield, stability, and adaptability has become primary areas of interest for breeders in the region.

Grain yield, stability, and adaptability are highly influenced by environment (Singh et al., 2014). Wheat genotypes must be tested in multi-environment yield trials (MEYT) to determine grain yield, stability, genotype by environment interaction (GEI), adaptability, and to identify a potential candidate to release for commercial cultivation (Yan et al., 2001; Kaya et al., 2006). The GEI plays a critical role in determining the stability of the genotype (Verma et al., 2015). The GEI reduces the correlation between phenotypic and genotypic variances and confounds selection of the best genotypes (Ebdon and Gauch, 2002). Variability among the test environments is also one of the most important factors for determining of stability of genotypes (Mohammadi et al., 
2012). Therefore, determining and understanding the structure of GEI is very important for any plant breeding program.

Combined analysis of variance (ANOVA) does not estimate non-additive interaction components. Therefore, there is a need to identify different statistical techniques to determine GEI. Statistical methods such as Eberhart and Russel (1966) regression, AMMI (additive main effect and multiplicative interaction) and GGE biplot (Genotype main effect and genotype by environment interaction) have been successfully utilized by plant breeders to estimate the stability of genotypes. Adaptability of genotypes can be further classified into general and specific adaptability. The genotypes that yield better across different environments are known to have general adaptability and the genotypes that yield better in specific environment are known to have specific adaptability.

In Eberhart and Russel (1966) regression method stability of genotypes is determined by regressing the mean value of each genotype on the environmental index or means of the environment. In this method both regression coefficient $\left(b_{i}\right)$ and deviation from regression $\left(S_{d i}^{2}\right)$ are taken into consideration to measure stability of genotypes. According to Eberhart and Russell (1966), genotype with higher mean yield, a regression coefficient of unity $\left(b_{i}=1\right)$, and deviation from regression of zero $\left(S_{d i}^{2}=0\right)$ showe better general adaptability across environments. Genotypes with $\mathbf{b}_{\mathbf{i}}>1.0$ are more responsive to high yielding environments and those with $\mathbf{b}_{\mathbf{i}}<1.0$ are more responsive to low yielding environments.

Multivariate techniques such as AMMI and GGE biplot methods are used to characterize genotype and environment main effects and principal component analysis to characterize their interactions. Hagos and Abay (2013) reported that AMMI model and GGE-biplot analysis are powerfull methods for determining GEI patterns. AMMI can determine genotype stability across locations by principal component analysis (PCA) and AMMI stability value (ASV). Genotypes with small PCA and ASV scores are considered as a stable in AMMI method. However, AMMI biplot doesn't have inner product property of a biplot, which is underpinning the biplot analysis (Samonte et al., 2005). Hence, AMMI biplot does not display the discriminating ability and representative view of a biplot which is effective in evaluating test environment (Yan and Hunt, 2001). The GGE biplot analysis considers genotype and GE simultaneously thus comprehensively explains GEI and is more informative than AMMI. Therefore, GGE biplot is more commonly used in MEYT to effectively identify best genotypes for each test environment, across environments, and mega-environments. It is constituted by first two main components (PC1 and PC2), which originated from environment, genotype, and GEI variations. Genotypes with high PC1 and small PC2 (close to zero) scores are considered as stable genotypes (Yan and Hunt, 2001).

We evaluated 20 advanced breeding lines and five bread wheat cultivars for grain yield and statistical analysis were performed following AMMI, GGE biplot methodology and non-parametric methods $\left(\mathbf{b}_{\mathbf{i}}\right.$ and $\left.\mathbf{s}^{\mathbf{2}} \mathbf{d}_{\mathbf{i}}\right)$. The aims to use these methods were (i) to determine grain yield and stability of 25 bread wheat genotypes in southeastern Turkey (ii) to compare GGE biplot and AMMI with Eberhart and Russel (1966) and graphically display relation among genotypes and environments (iii) to determine mega-environments in southeastern Turkey for wheat cultivation, and (iv) to identify potential candidate lines for registration and release as a variety(s). 


\section{Materials and methods}

Twenty bread wheat genotypes and five largely grown check cultivars (Table 1) were evaluated across ten rain-fed locations (environments) (Table 2 and Fig. 1) in southeastern Turkey in 2010-11 growing season. South-east Anatolia Region has semiarid climatic conditions, in summer hot and in winter cold, most of precipitation occurs in winter months. The soil character in test environments is red-brown and deep with $\mathrm{ABC}$ zonal profile. Soil in region has high $\mathrm{pH}$, alkaline, high calcium content, low organic matter, high potassium and moderate phosphorus content.

Trials were laid out in a randomized complete block design (RCBD) with four replications. All trials were planted in six row plots measuring an area of $6 \mathrm{~m}^{-2}$ with a seeding rate of $200 \mathrm{~kg} \mathrm{ha}^{-1}$. The trials were supplemented with $60 \mathrm{~kg} \mathrm{ha}^{-1}$ urea and 120 $\mathrm{kg} \mathrm{ha}^{-1}$ DAP (Di ammonium phosphate) fertilizers at planting. Planting dates varied from $5^{\text {th }}$ to $20^{\text {th }}$ November, depending on weather conditions at each location. Topic- 15 WG at $37 \mathrm{~g}$ a.i. $\mathrm{ha}^{-1}$ were used for weeds control in all test environments.

Data were collected for grain yield $\left(\mathrm{GY} ; \mathrm{t} \mathrm{ha}^{-1}\right)$, thousand grain weight $(\mathrm{TGW} ; \mathrm{g})$, test weight (TW; $\mathrm{kg} / \mathrm{hl})$, plant height $(\mathrm{PH} ; \mathrm{cm})$, days to heading (HD) according to Kilıç et al. (2010); protein content (PC; \%) and Mini Sds sedimentation (MSDS; ml) according to Payne et al. (1984). Yield stability statistics were calculated across ten locations using Eberhart and Russel (1966) regression method, AMMI, and GGE biplot methods. Combined ANOVA, AMMI, and GGE biplot analysis were done by using GenStat $12^{\text {th }}$ (Gen Stat 2009) statistical software. Eberhart and Russell stability statistics were computed by SAS software (SAS Institute, 1999).

\section{Eberhart and Russell analysis}

Eberhart and Russell model (1966) was used to determine yield stability of genotypes for $\mathbf{b}_{\mathbf{i}}$ (Regression Coefficient) and $S_{d i}^{2}$ (deviation from the regression) according to the following formula:

$$
Y_{i j}=\mu_{i}+b_{i} l_{j}+s^{2} d_{i j}
$$

Where $\mathbf{Y}_{\mathbf{i j}}$ is the mean performance of $\mathbf{i}^{\text {th }}$ genotype in $\mathbf{j}^{\text {th }}$ location, $\boldsymbol{\mu}_{\mathbf{i}}$ is the mean of $\mathbf{i}^{\text {th }}$ genotype acroos all environments; $\mathbf{b}_{\mathbf{i}}$ is the regression coefficient which calculated the response of the $\mathbf{i}^{\text {th }}$ genotype to varying environments, $\mathbf{s}^{2} \mathbf{d i j}$ is the deviation from regression of $\mathbf{i}^{\text {th }}$ genotype in the $\mathbf{j}^{\text {th }}$ environment, and $\mathbf{l}_{\mathbf{j}}$ is the environmental index of $\mathbf{j}^{\text {th }}$ environment.

\section{AMMI analysis}

For AMMI model following formula was used:

$$
\mathrm{Y}_{\mathrm{ger}}=\mu+\alpha_{\mathrm{g}}+\beta_{\mathrm{e}}+\sum_{\mathrm{n}} \lambda_{\mathrm{n}} \gamma_{\mathrm{gn}} \delta_{\mathrm{en}}+\varepsilon_{\mathrm{ger}}+\rho_{\mathrm{ge}}
$$

where $\mathbf{Y}_{\text {ger }}$ is yield of genotype (g) in environment (e) for replication (r).

Additive parameters: $\boldsymbol{\mu}$ is the grand mean; $\boldsymbol{\alpha}_{\mathbf{g}}$ is the deviation of genotype $\mathbf{g}$ from the grand mean; $\boldsymbol{\beta}_{\mathbf{e}}$ is the deviation of environment $(\mathbf{e})$

Multiplicative parameters: $\lambda_{n}$ is the singular value for (IPCA) $n, \gamma_{\mathbf{g n}}$ is the genotype eigen vector for axis $\mathbf{n}$, and $\boldsymbol{\delta}_{\mathbf{e n}}$ is the environment eigen vector; $\boldsymbol{\varepsilon}_{\mathbf{g e r}}$ is error term and $\boldsymbol{\rho}_{\mathbf{g e}}$ are PCA residuals. Genotypes with low IPCA scores expresses general adaptability 
whereas genotypes with high IPCA have specific adaptability (Gauch and Zobel, 1996; Lule et al., 2014).

GEI was analyzed in AMMI model (Zobel et al., 1988; Gauch, 2006) to determine large adaptability genotypes. AMMI's stability value (ASV) was calculated for each genotype and environment according to Purchase (1997) using formula:

$$
\sqrt{ }\left[\left(S_{I P C A 1} / S S_{I P C A 2}\right)(I P C A 1 \text { score })\right]^{2}+(\text { IPCA2 score })^{2}
$$

Where $S S_{I P C A 1} / S S_{I P C A 2}$ is the weight given to the IPCA1 by dividing IPCA1 SS by the IPCA2 SS. IPCA1 and IPCA2 scores are genotypic scores in the AMMI model.

ASV is a distance between a coordinate point and the origin on a two-dimensional plot of IPCA1 scores against IPCA2 scores in AMMI model (Purchase, 1997). ASV was calculated for each genotype and environment according to the relative contribution to IPCA1 to IPCA2 and to interaction sum of square. Because the IPCA1 score largely contribute to GEI sum of squares genotypes with low ASV is considered largely adapted. Similarly IPCA2 score close to zero show higher stability while higher values of IPCA2 indicate more specific adaptation and lower stability.

\section{GGE-biplot analysis}

GGE biplot was performed according to Yan and Hunt (2001). GGE biplot is a multivariate analytical technique that graphically displays a two way table and allows visualizing the relation among entries, testers, and their interactions (Yan, 2001). The GGE-biplot shows the first two principal components (PC1 and PC2) derived from subjecting environment-centered yield data (yield variation due to GGE) to singular value decomposition (Yan et al., 2000).

Table 1. Genotypes with code and origin

\begin{tabular}{|c|c|c|c|c|c|}
\hline Code & Genotypes & Origin & Code & Genotypes & Origin \\
\hline G1 & $\begin{array}{l}\text { Spn/Nac//Attila } \\
\text { Shuha-7//Seri82/Shuha }\end{array}$ & Cimmyt & G14 & $\begin{array}{l}\text { Kauz//Star/Luco- } \\
\mathrm{M} / 5 / \text { Bow/Crow//Buc/Pvn/3/Vee } \\
\# 10 / 4 /\end{array}$ & CIMMYT \\
\hline G2 & 'S2 & Icarda & G15 & Cemre (Check) & TURKEY \\
\hline G3 & Wh542//Galvez/Weave & Cimmyt & G16 & Finsi F 2000 & CIMMYT \\
\hline G4 & Sunco/2*Pastor & Cimmyt & G17 & $\begin{array}{l}\text { Mv17//Atila/Bcl } \\
\text { 3/4/Ppb8- }\end{array}$ & IWWIP \\
\hline G5 & Nurkent (Check) & Turkey & G18 & $\begin{array}{l}\text { 68/Chrc/3/Pyn//Tam101/Amigo } \\
\text { Vee\#8//Jup/Bjy/3/F3.71/Trm/4/B }\end{array}$ & CIMMYT \\
\hline G6 & $\begin{array}{l}\text { Sara/Thb//Vee/3/Bjy/Co } \\
\text { c//Prl/Bow }\end{array}$ & Cimmyt & G19 & $\begin{array}{l}\text { cn/5/Kauz/6/163hamidiye//Vee/ } \\
\text { Koel/6/Tam200/Kauz }\end{array}$ & IWWIP \\
\hline G7 & $\begin{array}{l}\text { Attila//Pgo/Seri/3/Pastor } \\
\text { Pastor/3/Prl/Sara//Tsivee }\end{array}$ & Cimmyt & G20 & Sagitario (Check) & ITALY \\
\hline G8 & \#5 & Cimmyt & $\mathrm{G} 21$ & Kauz/Pastor & CIMMYT \\
\hline G9 & Fret2/Tukuru//Fret2 & Cimmyt & $\mathrm{G} 22$ & Mino & CIMMYT \\
\hline G10 & $\begin{array}{l}\text { Pehlivan (Check) } \\
\text { Nac/Th.Ac//3*Pvn/3/Mir }\end{array}$ & Turkey & $\mathrm{G} 23$ & Krichauff/Finsi & \\
\hline G11 & $\begin{array}{l}\text { lo/Buc/4/2*Pastor } \\
\text { Nac/Th.Ac//3*Pvn/3/Mir }\end{array}$ & Cimmyt & G24 & T.Tau.83.2.36/Attila & IWWIP \\
\hline $\begin{array}{l}\text { G12 } \\
\text { G13 }\end{array}$ & $\begin{array}{l}\text { lo/Buc/4/2*Pastor } \\
\text { Wbll1*2/Tukuru }\end{array}$ & $\begin{array}{l}\text { Cimmyt } \\
\text { Cimmyt }\end{array}$ & G25 & Adana -99 (Check) & TURKEY \\
\hline
\end{tabular}


Table 2. Test environments with code, altitude, coordinate and rainfall in cropping seasons of 2010-11.

\begin{tabular}{llccc}
\hline $\begin{array}{l}\text { Test environment } \\
\text { Code }\end{array}$ & Location & Altitude $(\mathrm{m})$ & Coordinates & $\begin{array}{c}\text { Rainfall in } \\
2010-11 \text { season } \\
(\mathrm{mm})\end{array}$ \\
\hline E1 & Hazro & 1050 & $38^{0} 15^{\prime} \mathrm{N} 40^{\circ} 46^{\prime} \mathrm{E}$ & 550 \\
E2 & Derik & 850 & $37^{\circ} 21^{\prime} \mathrm{N} 40^{\circ} 16^{\prime} \mathrm{E}$ & 391 \\
E3 & Silvan & 840 & $38^{0} 08^{\prime} \mathrm{N} 41^{0} 05^{\prime} \mathrm{E}$ & 610 \\
E4 & Diyarbakır & 600 & $37^{0} 54^{\prime} \mathrm{N} 40^{\circ} 14^{\prime} \mathrm{E}$ & 685 \\
E5 & Adiyaman & 582 & $37^{\circ} 46^{\prime} \mathrm{N} 38^{0} 30^{\prime} \mathrm{E}$ & 602 \\
E6 & Ergani & 950 & $38^{0} 16^{\prime} \mathrm{N} 39^{0} 45^{\prime} \mathrm{E}$ & 670 \\
E7 & Kizltepe & 484 & $37^{\circ} 11^{\prime} \mathrm{N} 40^{0} 35^{\prime} \mathrm{E}$ & 315 \\
E8 & Bismil & 535 & $37^{\circ} 50^{\prime} \mathrm{N} 40^{0} 39^{\prime} \mathrm{E}$ & 450 \\
E9 & Cinar & 680 & $37^{0} 43^{\prime} \mathrm{N} 40^{\circ} 24^{\prime} \mathrm{E}$ & 494 \\
E10 & Sanliurfa & 360 & $36^{0} 55^{\prime} \mathrm{N} 39^{0} 54^{\prime} \mathrm{E}$ & 480 \\
\hline
\end{tabular}

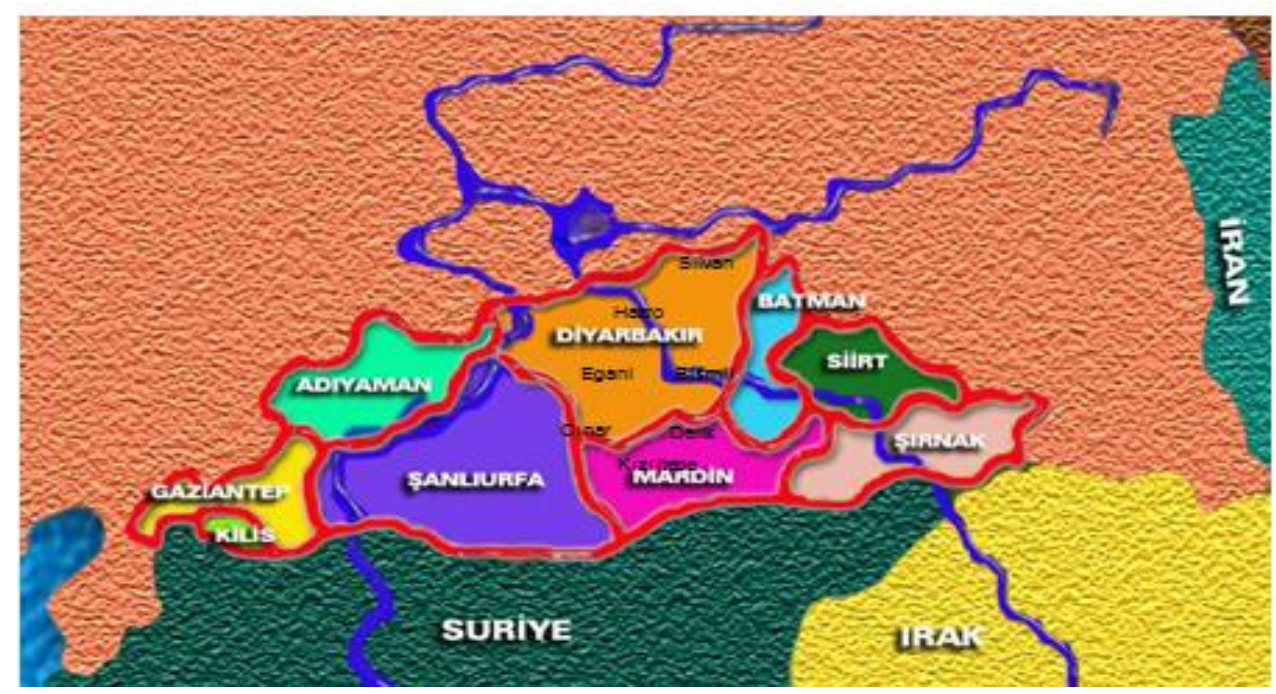

Figure 1. Map of South-East Anatolia Region and test environments

\section{Results}

\section{Combined ANOVA}

Combine ANOVA analysis across ten environments showed that there is a highly significant difference between genotypes and environments for grain yield (Table 3). Significant GEI indicated that wheat genotypes showed different responses across test environments. Therefore, determining the stability of genotypes will help in identifying potential genotypes to be released with broad and specific adaptability. Combined ANOVA showed that environment explained a major portion of the total variation (75.9\%) followed by GEI (8\%) and genotype (2.6\%) (Table 3). Mean grain yield of genotypes was $6.02 \mathrm{t} \mathrm{ha}^{-1}$ and ranged from 5.4 to $7.0 \mathrm{t} \mathrm{ha}^{-1}$. Grain yield average of test environments ranged from 3.57 to $8.89 \mathrm{t} \mathrm{ha}^{-1}$. Environments E1, E3, E4, E5, and E6 had higher grain yield than the average, whereas E2, E7, E8, E9, and E10 displayed lower grain yield than the average. 


\section{Eberhart and Russell regression model}

Eberhart and Russell regression was performed with nonparametric stability $\left(\boldsymbol{b}_{\boldsymbol{i}}\right.$ and $\boldsymbol{s}^{2} \boldsymbol{d}_{i}$ ) parameters to calculate the stability of 25 wheat genotypes (Table 6 ). The regression coefficient $\left(\mathbf{b}_{\mathbf{i}}\right)$ values of 25 genotypes were between 0.65-1.24 in the present study (Table 6). The large variation in $\boldsymbol{b}_{\boldsymbol{i}}$ values indicated that 25 genotypes showed different performance across various environments. Deviation from regression $\left(\mathbf{s}^{\mathbf{2}} \mathbf{d}_{\mathbf{i}}\right)$ values of tested genotypes ranged from 0.04 to 5.01 .

The genotypes G19 and G13 were determined as the best genotypes for wide scale release (broad adaptability) since they had higher grain yield than other genotypes, regression coefficient values $\left(\mathbf{b}_{\mathbf{i}}\right)$ close to one (1.01 and 1.03 , respectively) and small deviation from the regression (0.99 and 0.63, respectively) (Table 6; Fig. 2). The genotypes G12 and G7 were classified as the most stable genotypes (Table 6; Fig. 2) since their regression coefficient is close to one and had a low squared deviation from the regression coefficient. The genotype G4 classified as moderately stable genotype since its regression coefficient was close to 1 and had high deviation from regression value $\left(\boldsymbol{S}^{2} \boldsymbol{d}_{i}=1.52\right)$. The genotypes $\mathrm{G} 10, \mathrm{G} 11, \mathrm{G} 17$ and $\mathrm{G} 21$ had a regression coefficient less than one (bi<1.00), therefore these genotypes are recommended for low-yielding environments that require good agronomic practices (Table 6; Fig. 1). The genotypes G1, G23 and G9 with regression coefficient higher than one (bi>1.0) are better adapted to high-yielding areas and suitable for favorable growing conditions with apropropriate agronomic practices (Table 6; Fig. 2). The genotypes G5, G6, G14, G15 and G22 were classified as the worst genotypes for these environments; these genotypes had low grain yield, high $\mathbf{b}_{\mathbf{i}}$, and high $\boldsymbol{S}^{2} \boldsymbol{d}_{i \text {. values (Table 6; Fig. 2) }}$

\section{Additive main effects and multiple interaction (AMMI) model}

The result of AMMI analysis showed highly significant $(\mathrm{P}<0.01)$ variation among genotypes, environments, GEI, and IPCAs (Table 4). In AMMI, a total variation of $86.49 \%$ was explained by G+E+GEI. Environment explained highest variation $(75.9 \%)$ of total variation followed by GE interaction (7.99\%) and genotype (2.60\%). This result indicates that the contribution of environmental effect was much higher than the effect of genotype for the variation in grain yield, possibly due to environmental variation. This suggests that environments of the current study can be sub-grouped into mega environments. The first three PCs explain $69.7 \%$ of total variation, while the first IPCA had $41 \%$ and second IPCA $17.1 \%$ (Table 4; Fig 3). The results of AMMI analysis with IPCA1 and IPCA2 are presented in Table 6. The higher IPCA scores either positive or negative, the more specifically adapted a genotype to certain environment. The more IPCA scores close to zero, the more stable the genotype is across environments (Gauch and Zobel, 1988). Small AMMI stability value (ASV) is an indicator of stable genotypes (Purchase, 1997). Genotypes displayed different ASV and IPCA1 scores in the present study. ASV score of G2, G5, G6, G9, G10, G14, G15, G20, G21, G22 and G25 were the highest and ranged from 1.15 to 2.94 while G3, G4, G7, G8, G11, G17, G18, G19 and G23 had moderate ASV scores ranged from 0.44 to 0.96 . The lowest ASV scores were displayed by G1, G12, G16 and G24 that ranged from 0.11 to 0.33 . Genotype G1 was the most stable genotypes with lowest IPCA1 and ASV scores, and it had higher grain yield than the average of MEYT. G12 was another stable genotype with low ASV score and yield performance almost equal to the average of MEYT. G19 and G13 were the moderately stable genotypes with moderate ASV and IPCA1 scores 
and reported to have highest mean grain yield. The genotypes G2, G14, G15, G20, G22, and G25 were classified as most unstable and interactive genotypes because of high ASV and IPCA score and these genotypes had low grain yield. G21 and G9 were also identified as most unstable genotypes with high ASV and IPCA1 scores but were reported to have appreciable yield performance. The genotype G24 had a lowest ASV score but its yield was lower than the average of MEYT.

The results of yield performance within a test environments are displayed in (Fig. 3). According to AMMI biplot and ASV score G12, G2, G24, G18, and G1 were the more stable genotypes, the genotypes G20, G21, and G22 were unstable genotypes. AMMI biplot (Fig. 3) also indicated a relationship between test environments and demonstrated that environments can be classified into two mega-environments. These results showed that the first group of environments E1, E3, E5, E6, and E4 can be classified into megaenvironment one and E2, E8, and E9 into mega-environments two. A list of best three genotypes for each test environment based on AMMI biplot analysis is presented in Table 5. According to AMMI biplot analysis the genotypes G10 and G13 were best for environments E1, E2, E3, E4, E5, E6 and E7; the genotype G19 is best for E2, E4, E5, E6 and E7, whereas genotype G21 is best for E8 and E9.

\section{Genotype and Genotype by Environment Interaction (GGE) biplot analysis}

The results of GGE biplot analysis for 25 bread wheat genotypes tested across ten environments are presented in Figure 4 to Figure 8. In this study, PC1 captured $53.60 \%$ and the PC2 captured $32.84 \%$ of the total variation, these two PCs accounted for $86.43 \%$ of the total variation.

Table 3. Combined ANOVA of grain yield and other traits for 25 bread wheat genotypes in 10 environments

\begin{tabular}{|c|c|c|c|c|c|c|c|c|c|c|}
\hline \multicolumn{6}{|c|}{ Grain yield } & \multicolumn{5}{|c|}{ Mean squares } \\
\hline Source & Df & SS & MS & $\begin{array}{l}\mathrm{F} \\
\text { Ratio }\end{array}$ & $\begin{array}{l}\text { Exp. } \\
(\%)\end{array}$ & TW & TGW & $\mathrm{PH}$ & Msds & PC \\
\hline $\mathrm{E}$ & 9 & 31092849 & 3454761 & $194 * *$ & 75.9 & $1438.7 * *$ & $3209 * *$ & $11520 * *$ & $933 * *$ & $932.7 * *$ \\
\hline Rep & 30 & 534271 & 17809 & $2.57 * *$ & 1.3 & $0.2 \mathrm{~ns}$ & $194 \mathrm{~ns}$ & $0.07 \mathrm{~ns}$ & $15.6^{*}$ & $15.7 * *$ \\
\hline $\mathrm{G}$ & 24 & 1046390 & 43599.6 & $6.28 * *$ & 2.6 & $78.2 * *$ & $805^{* *}$ & $1906 * *$ & $\begin{array}{l}117 * * \\
12.9\end{array}$ & $117.4 * *$ \\
\hline $\mathrm{G} \times \mathrm{E}$ & 216 & 3271555 & 15146.1 & $2.18 * *$ & 8.0 & $5.8 * *$ & $468 * *$ & $108 * *$ & $* *$ & $12.9 * *$ \\
\hline Error & 720 & 4998928 & & & & 720 & $154 * *$ & $6.6 * *$ & $0.61 * *$ & $0.58 * *$ \\
\hline Total & 999 & 40943994 & & & & 17.1 & $267 * *$ & $178 * *$ & $14.9 * *$ & $14.9 * *$ \\
\hline CV (\%) & & 13.8 & & & & 1.5 & 2.1 & 1.3 & 4.5 & 2.3 \\
\hline
\end{tabular}

\section{Relationship between environments and traits by GGE biplot}

The GGE biplot for seven traits in ten environments showed that PC1 explained $60.18 \%$ of the genotype and GEI effects while PC2 explained $19.1 \%$ of the total 79.28 \%. (Fig. 7). Interrelationship among the traits is presented in Fig. 6. An obtuse $\left(>90^{\circ}\right)$ angle indicates a negative correlation, an acute angle indicates a positive correlation, and a right angle is indicative of absence of correlation. These results showed negative correlations between yield components (GY, TKW, TW, and $\mathrm{PH})$ and quality traits (Msds and PC), as well as GY and HD. 
Table 4. Combined AMMI analysis of variance genotypes per for grain yield

\begin{tabular}{lccccc}
\hline Source & DF & SS & MS & F val. & $\begin{array}{c}\text { Exp. } \\
(\%)\end{array}$ \\
\hline Total & 999 & 40944 & 41.0 & & \\
Treatments & 249 & 35411 & 142.2 & $20.5^{* *}$ & \\
Genotypes & 24 & 1046 & 43.6 & $6.3^{* *}$ & 2.60 \\
Environment & 9 & 31093 & 3455 & $193.9 * *$ & 75.9 \\
Blocks & 30 & 534 & 17.8 & 2.6 & \\
Interactions & 216 & 3272 & 15.1 & $2.2^{* *}$ & 7.99 \\
IPCA & 32 & 1343 & 42.0 & $6.1 * *$ & 41.00 \\
IPCA & 30 & 557 & 18.6 & $2.7 * *$ & 17.10 \\
IPCA & 28 & 380 & 13.6 & $1.3 * *$ & 11.60 \\
Residuals & 126 & 991 & 7.9 & & \\
\hline Error & 720 & 4999 & 6.9 & & \\
\hline
\end{tabular}

Table 5. AMMI selections of best environments

\begin{tabular}{cccccc}
\hline Env. & Mean & Score & 1 & 2 & 3 \\
\hline E1 & 6.28 & 0.38 & G13 & G19 & G9 \\
E2 & 4.23 & -0.36 & G19 & G21 & G4 \\
E3 & 7.48 & 0.62 & G13 & G19 & G9 \\
E4 & 8.89 & 0.58 & G19 & G22 & G25 \\
E5 & 6.91 & 0.76 & G19 & G13 & G9 \\
E6 & 8.44 & 0.63 & G19 & G9 & G13 \\
E7 & 3.57 & -0.07 & G19 & G13 & G21 \\
E8 & 5.31 & -1.15 & G21 & G19 & G4 \\
E9 & 4.85 & -1.57 & G21 & G20 & G10 \\
E10 & 4.31 & 0.18 & G19 & G13 & G9 \\
\hline
\end{tabular}

$* *=$ Significant at $1 \%$ probability level; $*=$ Significant at $5 \%$ probability level

d.f. $=$ degree of freedom; $S S=$ sum of square; $M S=$ mean square

\section{Relationship among genotypes and traits by GGE biplot}

The GGE biplot for seven traits of 25 bread wheat genotypes in 10 environments showed that PC1 explained $33.82 \%$ and PC2 explained $19.64 \%$ of the total $53.47 \%$ variation (Fig. 8). GGE biplot showed that the genotypes G19, G11, G14, G16, and G24 were the vertex genotypes for this study. The genotype G19 had the highest values for GY and HD, therefore, it could be used as parent to increase yield potential in breeding programs. The genotypes G11, G10, and G15 were the superior genotypes for TKW and PH. The genotype G16 had the highest value for TW. The genotype G14 had the best performance for MSDS and PC, hence it can be used as potential parent for quality improvement. Vector view of the genotypes by trait biplot (Fig. 8) reflected strong positive correlations between GY and TGW; TW and TGW; PC and MSDS.

\section{Which-Won-Where pattern of genotypes and environments based on grain yield}

Genotypes had different yield performances across environments. The polygon view of the GGE biplot for grain yield presents that which genotype is best for which mega environment (Fig. 3). The polygon is formed by connecting the genotypes that are furthest away (good or bad) from the origin of the biplot so that all genotypes are grouped within the polygon. The genotypes that formed the vertex of the polygon are more responsive to the environment. A sector is formed by drawing a perpendicular line between two adjacent genotypes that form the polygon (Yan and Kang, 2003). Genotypes G19, G13, G21, G6 and G20 were located in polygon corners and were far away from the origin. Overall, the genotypes G19, G13 and G21 were classified as best yielding genotypes, whereas G20 and G6 as the lowest yielding genotypes across the test environments. These genotypes are highly responsive to environmental variation. On the other hand, the genotypes G1, G16 and G12 that are located close to the center of origin were classified as least responsive to environmental changes and the grain yield capacity of these genotypes are moderate. Robio et al. (2004) indicated that genotypes located near the plot origin are less responsive to the environmental changes. 
Other useful features of the GGE biplot is the identification of mega-environments and their winning genotypes (Yan, 2001). The present investigation suggested the existence of two bread wheat growing mega-environments (ME1 and ME2) in the southeastern Turkey (Fig. 3). Among the testing environments, E1, E2, E3, E4, E5, E6, E7 and E10 fell inside ME1 while E8 and E9 fell inME2. The genotypes G19, G13, and G9 were high yielding genotypes in the ME1 and G21 in ME2.

\section{Relationship between test environments based on grain yield data}

Correlation between environments was calculated by using cosine of the angel between environments. A wide, obtuse angle between environments indicates a strong negative correlation, an acute angle indicates a positive correlation, and a close-to- $90^{\circ}$ angle indicates a lack of correlation (Yan and Tinker, 2006). Determination of the similarity of test environment helps to reduce numbers of the test environments required to discriminate genotypes. If two test environments are closely correlated consistently across years, one of them can be dropped without loss of much information about the genotypes (Farshadfar et al., 2012). GGE biplot results showed that environments in this study can be classified into two mega-environments. The environments E1, E4, E5 and E6 formed mega-environment one and E2, E7, E8, E9 and E10 as mega-environment two (Fig. 5). An environments with long vector indicates that the environment had greater discriminating ability and hence greater variation among genotypes, vice-versa for environments with short vector (Yan and Kang, 2003; Yan et al., 2007). Thus, the environments E4, E8, and E9 that had shorter vector were the least discriminating environments; E5, E6, and E7 that had medium vector were moderately discriminating and the environment E10 that had longest vectors was the most discriminating environment (Fig. 5). The test environment E10 is the best environment and E4 is worst environment to be able to the see differences between the genotypes.

\section{Average yield and stability of bread wheat genotypes based on grain yield}

The yield stability of genotypes was evaluated by an average environment coordination (AEC) method (Yan and Hunt, 2001; Rad et al., 2013). A line that is drawn through the biplot origin is called as the average environment axis and serve as absisca of the AEC. Genotypes are separated by AEC ordinate (Axis) and genotype which has a shorter absolute length of projection in either of the two directions of AEC ordinate (located closer to AEC abscissa) represents a smaller tendency of GEI, which means it is the most stable genotype across different environments (Yan and Kang, 2003). In the present study, genotypes with above average means were from G1 to G23 while genotypes with below average were from G25 to G2 (Fig. 5). Genotypes G21, G9, and G23 had high yield but longer vector indicating that these are suitable only for specific areas (Fig. 5). The genotypes G19 and G13 had the highest yield and shorter vector from the AEC lines indicating that these had better adaptability than G21, G9, and G23. Overall, the genotypes G20 and G6 classified as low yielding and low stable genotypes; G1, G12 and G16 as moderately yielding and highly stable and G21 and G9 as high yielding and unstable genotypes. 
Table 6. Mean grain yield $\left(t \mathrm{ha}^{-1}\right)$ for each environment with AMMI and regression analysis parameters

\begin{tabular}{|c|c|c|c|c|c|c|c|c|c|c|c|c|c|c|c|c|}
\hline Code & E1 & $\mathrm{E} 2$ & E3 & E4 & E5 & E6 & E7 & E8 & E9 & E10 & Mean & $b_{i}$ & $\mathrm{~s}^{2} \mathrm{~d}_{\mathrm{i}}$ & ASV & IPCA1 & IPCA2 \\
\hline G1 & 6.19 & 4.26 & 7.39 & 9.46 & 6.96 & 8.61 & 3.56 & 5.58 & 4.70 & 4.40 & 6.11 & 1.06 & 0.31 & 0.15 & 0.057 & -0.32 \\
\hline G2 & 5.95 & 4.33 & 7.03 & 8.73 & 6.44 & 8.08 & 3.50 & 5.91 & 5.49 & 4.15 & 5.96 & 0.89 & 1.07 & 1.18 & -0.49 & -0.13 \\
\hline G3 & 6.39 & 4.32 & 7.56 & 8.27 & 6.81 & 8.23 & 3.66 & 5.24 & 5.30 & 4.25 & 6.00 & 0.9 & 0.39 & 0.59 & -0.19 & 0.35 \\
\hline G5 & 6.31 & 3.83 & 7.64 & 8.86 & 7.11 & 8.54 & 3.33 & 4.42 & 3.83 & 4.18 & 5.80 & 1.13 & 1.17 & 1.28 & 0.53 & 0.08 \\
\hline G6 & 6.46 & 3.51 & 7.87 & 7.67 & 7.08 & 8.21 & 3.18 & 3.34 & 3.52 & 3.89 & 5.47 & 1.09 & 4.98 & 1.89 & 0.72 & 0.77 \\
\hline G7 & 5.97 & 4.23 & 7.12 & 9.41 & 6.71 & 8.42 & 3.45 & 5.78 & 4.85 & 4.28 & 6.02 & 1.02 & 0.74 & 0.52 & -0.13 & -0.42 \\
\hline G8 & 5.83 & 3.84 & 7.03 & 8.83 & 6.55 & 8.14 & 3.16 & 5.05 & 4.34 & 3.96 & 5.67 & 1.04 & 0.10 & 0.44 & 0.05 & -0.18 \\
\hline G9 & 6.66 & 4.28 & 7.97 & 9.47 & 7.50 & 8.98 & 3.75 & 5.02 & 4.29 & 4.62 & 6.25 & 1.13 & 0.84 & 1.17 & 0.49 & -0.05 \\
\hline G10 & 6.58 & 4.57 & 7.70 & 7.70 & 6.76 & 8.08 & 3.87 & 5.41 & 6.03 & 4.29 & 6.10 & 0.78 & 1.78 & 1.39 & -0.50 & 0.70 \\
\hline G11 & 6.40 & 4.56 & 7.52 & 8.64 & 6.83 & 8.35 & 3.81 & 5.80 & 5.69 & 4.42 & 6.20 & 0.88 & 0.49 & 0.93 & -0.38 & 0.15 \\
\hline G12 & 6.42 & 4.21 & 7.65 & 8.67 & 7.02 & 8.46 & 3.61 & 5.05 & 4.78 & 4.32 & 6.02 & 1.00 & 0.19 & 0.30 & 0.09 & 0.19 \\
\hline G13 & 6.94 & 4.57 & 8.22 & 9.08 & 7.58 & 8.97 & 4.03 & 5.21 & 4.96 & 4.76 & 6.43 & 1.03 & 0.63 & 0.69 & 0.26 & 0.27 \\
\hline G14 & 6.57 & 3.78 & 7.95 & 8.13 & 7.22 & 8.44 & 3.40 & 3.84 & 3.85 & 4.13 & 5.73 & 1.08 & 3.34 & 1.61 & 0.62 & 0.59 \\
\hline G15 & 6.18 & 3.74 & 7.54 & 9.51 & 7.20 & 8.74 & 3.24 & 4.50 & 3.38 & 4.24 & 5.83 & 1.22 & 1.79 & 1.77 & 0.73 & -0.28 \\
\hline G16 & 6.40 & 4.21 & 7.61 & 8.36 & 6.90 & 8.30 & 3.60 & 5.03 & 4.97 & 4.24 & 5.96 & 0.95 & 0.32 & 0.33 & -0.03 & 0.32 \\
\hline G18 & 5.93 & 4.13 & 7.07 & 8.74 & 6.51 & 8.12 & 3.37 & 5.51 & 5.00 & 4.08 & 5.85 & 0.95 & 0.34 & 0.61 & -0.25 & -0.12 \\
\hline G19 & 6.90 & 5.23 & 8.04 & 10.39 & 7.63 & 9.36 & 4.43 & 6.86 & 5.92 & 5.25 & 7.00 & 1.01 & 0.99 & 0.65 & -0.19 & -0.46 \\
\hline G20 & 5.39 & 4.09 & 6.31 & 7.15 & 5.43 & 7.00 & 3.12 & 5.85 & 6.28 & 3.47 & 5.41 & 0.65 & 5.01 & 2.94 & -1.21 & 0.31 \\
\hline G21 & 6.19 & 4.89 & 7.18 & 9.33 & 6.64 & 8.40 & 3.94 & 6.90 & 6.35 & 4.57 & 6.44 & 0.84 & 3.27 & 1.94 & -0.79 & -0.34 \\
\hline G22 & 6.00 & 3.92 & 7.30 & 10.21 & 7.12 & 8.87 & 3.29 & 5.22 & 3.62 & 4.37 & 5.99 & 1.24 & 2.03 & 1.51 & 0.55 & -0.74 \\
\hline G23 & 6.63 & 4.23 & 7.92 & 8.96 & 7.33 & 8.74 & 3.70 & 4.86 & 4.46 & 4.48 & 6.13 & 1.07 & 0.73 & 0.90 & 0.37 & 0.18 \\
\hline G24 & 5.93 & 3.94 & 7.12 & 8.75 & 6.60 & 8.17 & 3.26 & 5.12 & 4.53 & 4.02 & 5.74 & 1.01 & 0.04 & 0.11 & -0.01 & -0.10 \\
\hline G25 & 6.13 & 3.99 & 7.41 & 9.76 & 7.11 & 8.76 & 3.38 & 5.14 & 3.92 & 4.36 & 5.99 & 1.17 & 0.98 & 1.15 & 0.44 & -0.46 \\
\hline Mean & 6.28 & 4.23 & 7.48 & 8.89 & 6.91 & 8.44 & 3.57 & 5.31 & 4.85 & 4.31 & 6.03 & & 1.34 & 1.04 & 0.00 & 0.00 \\
\hline Lsd & $1.39^{\mathrm{ns}}$ & $0.96^{* *}$ & $0.10^{* *}$ & $1.62^{*}$ & $0.10^{* * *}$ & $0.73^{* * *}$ & $0.62^{* * *}$ & $0.93^{* *}$ & $1.89^{* *}$ & $0.95^{* *}$ & $0.37^{* * *}$ & & & & & \\
\hline
\end{tabular}

$* *=$ Significant at $1 \%$ probability level $; *=$ Significant at $5 \%$ probability level; $E=$ Environment, G=Genotype 


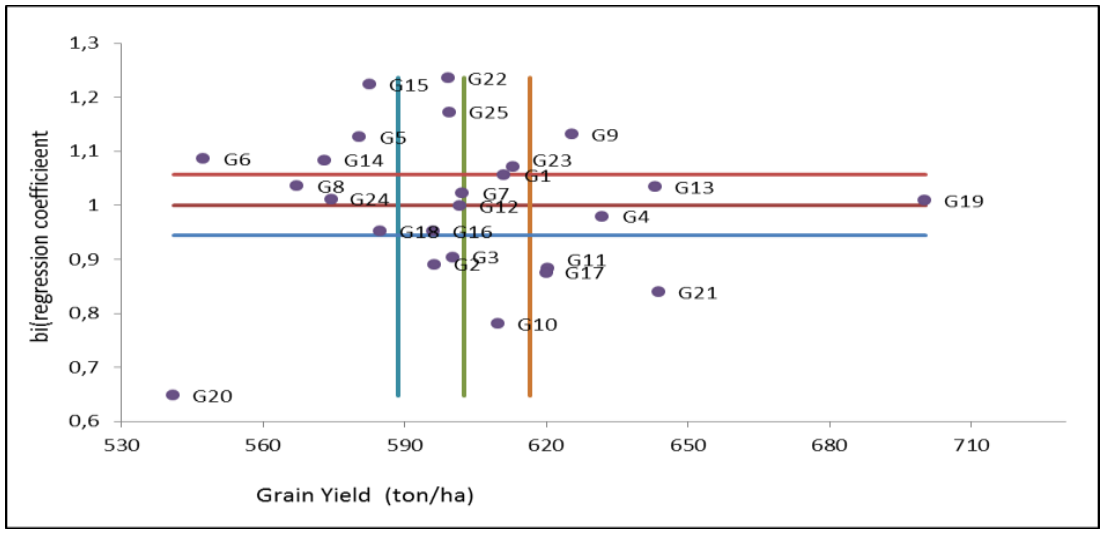

Figure 2. Scatter plot of regression coefficient against mean yield of 25 bread wheat genotypes

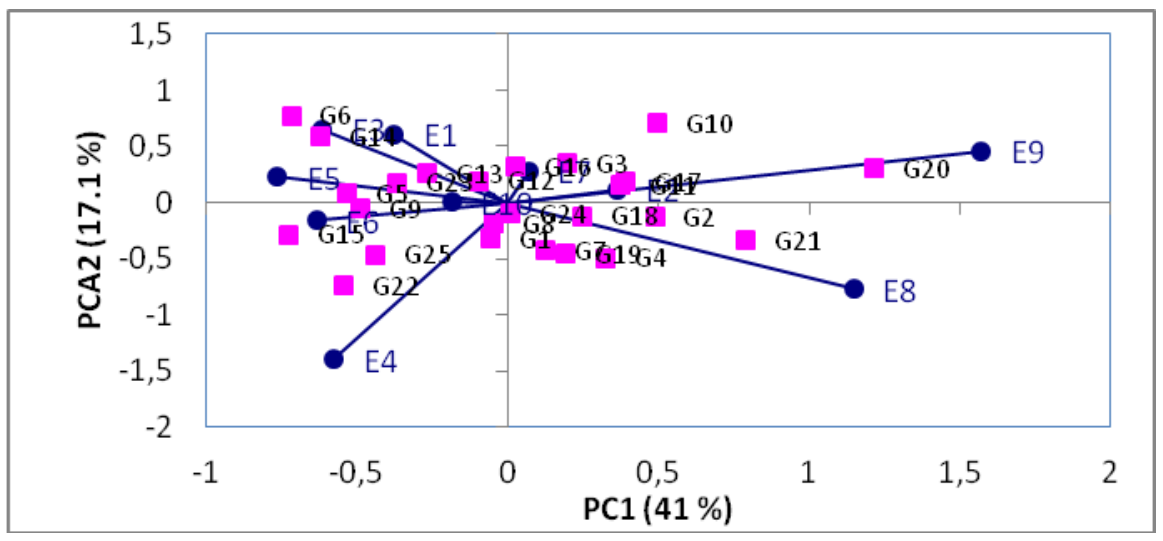

Figure 3. AMMI biplot of wheat genotypes and environments for grain yield

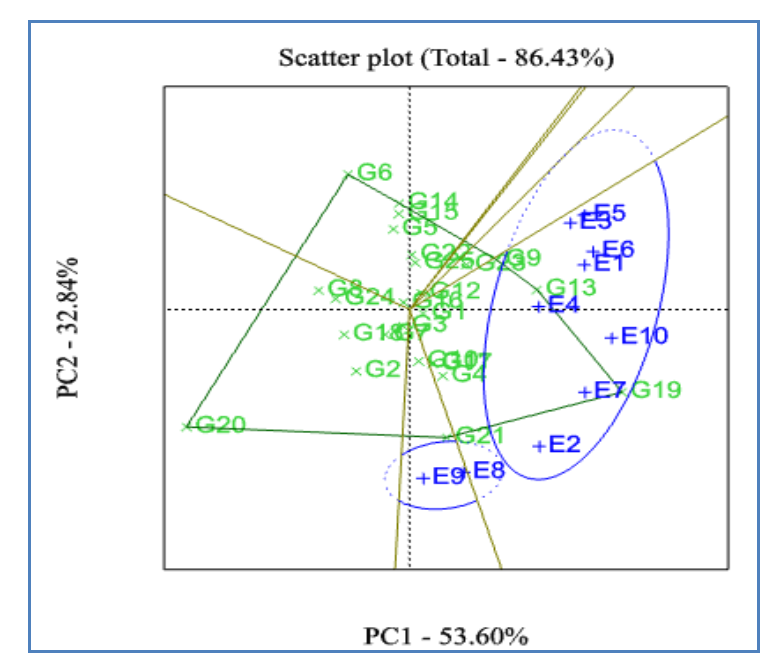

Figure 4. The which-won-where feature of GGE biplot for grain yield

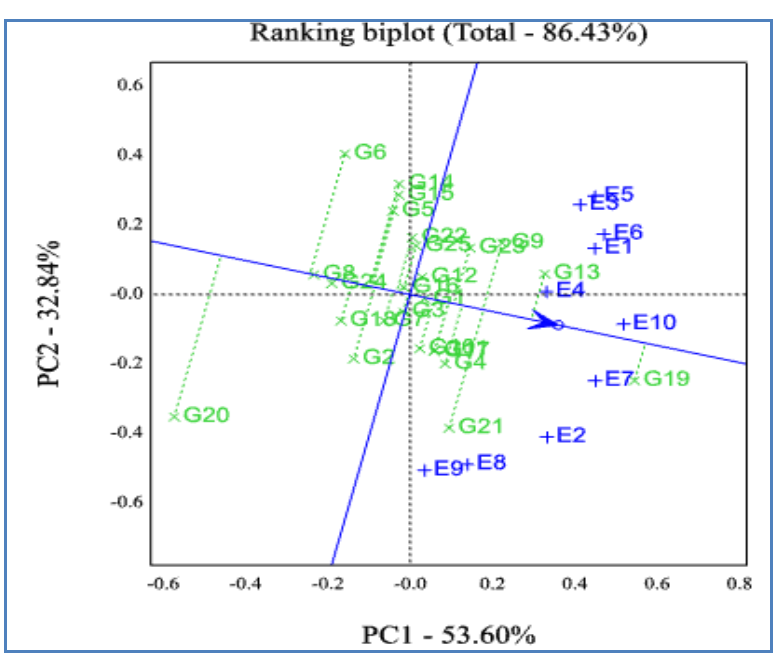

Figure 5. GGE biplot showing ranking for stability across environments

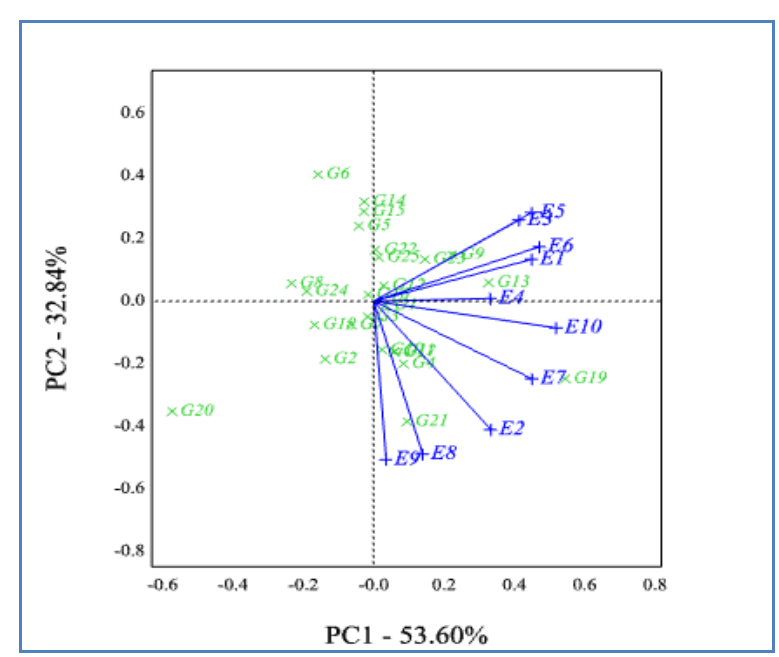

Figure 6. GGE biplot showing relation between test environments 


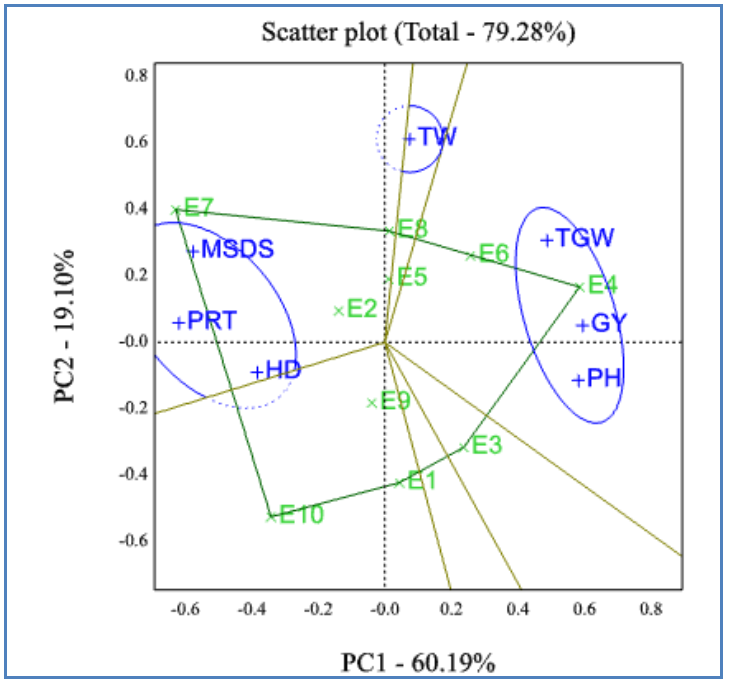

Figure 7. The which-won-where feature of the GGE biplot showing relation among traits and environment

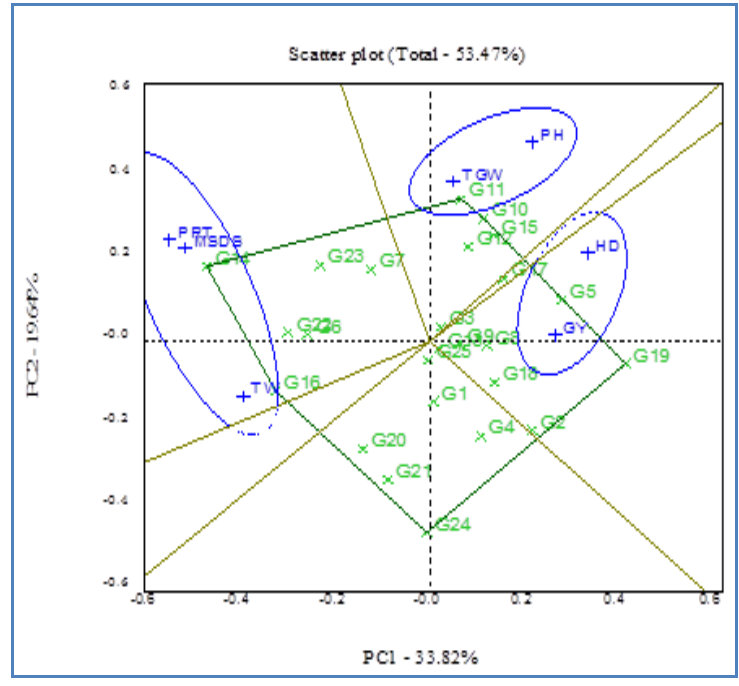

Figure 8. The which-won-where feature of the GGE biplot showing relation among traits and genotypes

\section{Discussion}

Plant breeders are using different statistical models to describe GEI and to recommend best genotype for each mega environment. Eberhart and Russell model (1966), AMMI, and GGE biplot methods were used to display stability and to explain variation among genotypes and the GEI. Presence of significant GEI illustrates differential response of genotypes across the test environments. The presence of GEI in the study affects the usefulness of the genotypes by confounding genotype performance, this necessitates estimating stability using Eberhart and Russell model or AMMI or GGE biplot. Results of grain yield and stability facilitate breeders to recommend best genotype for each specific environment.

In our study GGE biplot and AMMI explained 86.43 and $86.49 \%$ total variation, respectively. This results indicated that both AMMI and GGE biplots were similary efficient in determining stability of a genotypes. Similar results were reported by Rad et al. (2013). On contrary Gauch (2006) reported that AMMI is not as efficient as GGE in visualizing GEI. Samonte et al. (2005) explained that GGE biplot is better than AMMI and others statistical methods in evaluation of mega environment and genotype because it explains more G+GGE interactions. Yan et al. (2007) suggested that AMMI is superior to GGE biplot in presenting conclusions but for which-won-where patterns AMMI is not effective compared to GGE biplot. Also, in Eberhart and Russell model it is possible to visualize position of genotypes on scatter plot that explain stability level and specific adapted genotypes. But this model is not informative for discriminating level of test environments (Namorato et al., 2009).

According to visually displaying of stability of genotypes with GGE biplot (Fig. 5), scatter plot of regression coefficient (Fig. 2), and AMMI biplot (Fig. 3) G12 was most stable genotype. Present study indicated that GGE biplot, AMMI biplot and scatter plot of regression coefficient showed similar results for the stability of genotypes, i.e. G1, G9, G10, G12, G13, G15, G20, G21, G22 and G24.

According to average enviroment coordination (AEC) of GGE biplot (Fig. 5), AMMI stability value (ASV; Table 6.) and two non-parametric stability parameters $\left(\mathbf{b}_{\mathbf{i}}\right.$ and $\mathbf{s}^{2} \mathbf{d}_{\mathbf{i}}$; 
Table 6.) gave the similar results related to stability of G9, G13, G19, G21, G23 and G20. Genotype G13 was high yielding also moderate stable by three methods. G13 and G19 were attractive for selection or recommendation in both favorable and unfavorable conditions with their appropriate GE interaction and highest yield for all stability methods and parameters of present study. Several research reported that an ideal genotype should have appreciable yield with good stability parameters (Farshadfar et al., 2012: Robio et al., 2004). Genotypes G1 was stable and high yielding according to both GGE biplot and ASV, wheares it was moderately stable by regression coefficient $\left(\mathbf{b}_{\mathbf{i}}\right)$ value. Several researchers have reported that although stability of the genotypes can be determined using different methods but GGE biplot method provides a better understanding of adaptation level of genotypes across different environments (Mortazavian et al., 2014; Hassanpanah, 2011). The GGE biplot is also suitable to determine level of discrimination of environments and specific adaptability of genotypes in a visual form thus is more useful compared to other methods (Abate et al., 2015).

Ability of test environments for effective selection of superior genotypes is also important features of GEI and biplot analysis. AMMI and which-won-where pattern of GGE biplot gave the similar results related to best genotypes across test environments (Table 5 and Fig. 4). These results indicated that GGE biplot and AMMI methods were similar in grouping the test environments and genotypes. Test environments by their effects E and PCA scores are displayed by AMMI biplot but it dosen't give information regarding environment's ability in identifying superior genotypes (Zobel et al., 1988). Nevertheless, GGE biplot provides selection of large and specific adaptable genotypes based on discriminating ability of environments and representativeness (Yan et al., 2007). Based on yield data, AMMI biplot (Fig. 3) and GGE biplot (Fig. 6) gave the same results for relationship among environments for both biplots; E1, E4, E5, E6 were similar environments included in first group, while E2, E7, E8, E9 and E10 were strongly correlated and included in second group. According to both GGE and AMMI biplots, test environments coluld be divided into two mega environments (ME). Similar results were obtained by Kaya et al. (2006) in a study conducted at Central Region of Turkey which also indicated that the Central Region of Turkey could be divided into 2 mega environments for wheat cultivation.

Testing of genotypes in an environment that has highest discriminating ability would help to reduce the number of trials required and hence the total cost (Tesfaye et al., 2008). According to vector view of GGE biplot, E10 had long vector length and small angle to average environment axes, this suggests that E10 environment had more discriminating ability of genotypes than other environments (Fig. 6). Kaya et al. (2006) reported that under limited resources trials in ME should include limited number of environments that have high discriminating ability of genotypes. According to present results E10 and E6 may be the better test environments to discriminate genotypes.

\section{Conclusion}

It was determined that AMMI and GGE biplot analyses have similar results but they are more effective than Eberhart and Russell analysis. This study also concluded that AMMI, Eberhart and Russel (1966) and GGE biplot gave similar results regarding the stability of the genotypes and also proved that GGE biplot was more useful and efficient method to evaluate discriminating ability of test environments to identify genotypes compared to AMMI and Eberhart and Russell. The genotypes G19 and G13 were 
determined to be the best genotypes for release in high yielding environments and were reported to have highest grain yield with moderate stability. The genotype G12 reported to be the most stable genotype with moderate grain yield and this can be a potential candidate for multi-environmental release. Also, it was concluded that G14 could be used as parent in breeding programs to improve quality traits. Test environments were divided into two Mega Environments which means that identification of genotypes in breeding program for southeast Turkey coluld be done with limited resources.

Acknowledgements. This study was financially supported by the Minister of the Agricultural Research , Turkey (Proj. no. TAGEM. TR. 2007674896), thanks to GAP Int. Agr. Res. Training Center, Diyarbakir)

\section{REFERENCES}

[1] Abate, F., Mekbib, F., Dessalegn, Y. (2015): GGE biplot analysis of multi-environment yield trials of durum wheat (Triticum turgidum Desf.) genotypes in North Western Ethiopia. - American J. Exp. Agriculture 8: 120-129.

[2] Aktaş, H., Kılıç, H., Kendal, E., Altıkat, A. (2010): Evaluation of yield and yield components of some bread wheat genotypes in Diyarbakir conditions. - Collaboration of University and Puplic and Industry Simposium, pp. 357-363.

[3] Ebdon, J.S., Gauch, H.G. (2002): Additive main effect and multiplicative interaction analysis of national turfgrass performance trials. I. Interpretation of Genotype $\times$ Environment Interaction. - Crop Science 42: 489-496.

[4] Eberhart, S.A., Russell, W.A. (1966): Stability parameters for comparing varieties. Crop Science 6: 36-40.

[5] Ekboir, J. (2002): CIMMYT 2000-2001 World wheat overview and outlook: Developing no-till packages for small-scale farmers. CIMMYT Institutional Multimedia Publications Repository. http://repository.cimmyt.org/

[6] Farshadfar, E., Safari, H., Jamshidi, B. (2012): GGE biplot analysis of adaptation in wheat substitution lines. - Int. J. Agri.- Crop Science 4: 877-881.

[7] Gauch, H.G., Zobel. R.W. (1988): Predictive and postdictive success of statistical analyses of yield trials. - Theor. Appl. Genetic 76: 1-10.

[8] Gauch, H.G., Zobel. R.W. (1996): AMMI analysis of yield trials. In Genotype-byenvironment Interaction (Kang, M.S. and H.G. Gauch, eds.), CRC Press, Boca Raton., FL, pp. 85-122.

[9] Gauch, H.G. (2006): Statistical Analysis of Yield Trials by AMMI and GGE. - Crop Science 46: 1488-1500.

[10] GenStat. (2009): GenStat for Windows (12th Edition) Introduction. VSN International, Hemel Hempstead.

[11] Hagos, G., Abay, F. (2013): AMMI and GGE biplot analysis of bread wheat genotypes in the Northern part of Ethiopia. - J. Plant Breed. Genetic 1: 12-18.

[12] Hassanpanah, D. (2011): Analysis of $\mathrm{G} \times \mathrm{E}$ interaction using the additive main effects and multiplicative interaction (AMMI) in Potato cultivars. - Afr. J. Biotechnology 10: 154-158.

[13] Kaya, Y., Akçura, M., Taner, S. (2006): GGE-Biplot analysis of multi-environment yield trials in bread wheat.- Turk. J. Agric. Forest 30: 325-337.

[14] Kılıç, H., Akçura, M., Aktaş, H. (2010): Assessment of parametric and non-parametric methods for selecting stable and adapted durum wheat genotypes in multi-environments. Not. Bot. Hort. Agrobot. Cluj-Napoca 38: 271-279.

[15] Lule, D., Tesfaye, K., Mengistu, G. (2014): Genotype by environment interaction and grain yield stability analysis for advanced Triticale (X. Triticosecale Wittmack) genotypes in Western Oromia, Ethiopia. - Ethiop. J. Science 37: 63-68. 
[16] Mohammadi, M., Karımızadeh, R., Hossinpour, T., Falahı, H.A., Khanzadeh, H., Sabaghnıa, N., Mohammadi, P., Armıon, M., Hosn1, M.H. (2012): Genotype $\times$ environment interaction and stability analysis of seed yield of durum wheat genotypes in dryland conditions. - Notulae Sci. Biologicae 4: 57-64.

[17] Mortazavian, S.M.M., Nikkhah, H.R., Hassani, F.A., Sharif-al-Hosseini, M., Taheri, M., Mahlooji, M. (2014): GGE biplot and AMMI analysis of yield performance of barley genotypes across different environments in Iran. - J. Agri. Sci. Technology 16: 609-622.

[18] Namorato, H., Mirand, G.V., Vagno de Souza, L., Rodrigues, L., DeLima, R.O., Mantovani, E.E. (2009): Comparing Biplot Multivariate Analyses with Eberhart and Russell' method for genotype x environment interaction. - Crop Breed. Appl. Biotecnology 9: 299-307.

[19] Payne P.I., Holt, L.M., Jackson, E.A., Law, C.N. (1984): Wheat storage proteins: their genetics and their potential for manipulation by plant breeding. Philosophical Transactions of the Royal Society London. 304: 359-371.

[20] Purchase, J.L. (1997): Parametric analysis to describe G x E interaction and yield stability in winter yield. Ph.D Thesis, Department of Agronomy, Faculty of Agriculture, University of Orange Free State, Bloemfontein. South Africa, pp. 4-83.

[21] Rad, M.R., Naroui-Abdul, M., Rafii, M.Y., Jaafar, H., Naghavis, M.R., Ahmadi, F. (2013): Genotype $\times$ environment interaction by AMMI and GGE biplot analysis in three consecutive generations of wheat (Triticum aestivum L.) under normal and drought stress conditions. - Aust. J. Crop Science 7: 956-96.

[22] Robio, J., Cubero, J.I., Martin, I.M., Suso, M.J., Flores, F. (2004): Biplot analysis of trait relations of white lupin in Spain. - Euphytica 135: 217-224.

[23] Samonte, S.O.P.B., Wilson, L.T., McClung, A.M., Medley, J.C. (2005): Targeting cultivars onto rice growing environments using AMMI and SREG GGE biplot analysis. - Crop Science 45: 2414-2424.

[24] SAS. (1999): SAS/STAT User's Guide, Version 8.2, 1st printing. Vol. 2. SAS Institute Inc, SAS Campus Drive, Gray, North Carolina.

[25] Singh, R., Herrera-Foessel, S., Huerta-Espino, J., Singh, S., Bhavani, S., Lan, C. (2014): Progress towards genetics and breeding for minor genes based resistance to Ug99 and other rusts in CIMMYT high-yielding spring wheat. - J. Integr. Agriculture 13: 255-261.

[26] Tesfaye, L., D'Egidio, M.D., Mohammed, A. (2008): Analysis of multi-environment yield trials in durum wheat based on GGE-biplot. - J. Food Agric. Environment 6: 217-221.

[27] Verma, A., Chatrath, R., Sharma, I. (2015): AMMI and GGE biplots for G×E analysis of wheat genotypes under rain fed conditions in central zone of India. - J. Appl. Nat. Science 7: 656-661.

[28] Yan, W., Hunt, L.A., Sheng, Q., Szlavnics. Z. (2000): Cultivar evaluation and mega environment investigation based on the GGE biplot. - Crop Science 40: 597-605.

[29] Yan, W. (2001): GGE biplot-A windows application for graphical analysis of multienvironment trial data and other types of two-way data. - Agron. Journal 93: 1111-1118.

[30] Yan, W., Cornelius, P.L., Crossa, J., Hunt. L.A.(2001): Two types of GGE biplots for analyzing multi-environment trial data. - Crop Science 41: 656-663.

[31] Yan, W., Hunt. L.A. (2001): Interpretation of genotype $\mathrm{x}$ environment interaction for winter wheat yield in Ontario. - Crop Science 41: 19-25.

[32] Yan, W., Tinker. N. (2006): Biplot analysis of multi-location trial data: principles and applications. - Can. J. Plant Science 86: 623-645.

[33] Yan, W., Kang, M.S. (2003): GGE biplot analysis: a graphical tool for breeders, geneticists, and agronomists. - (CRC Press: Boca Raton, FL).

[34] Yan, W., Kang, M.S., Ma, B., Wood, S., Cornelius, P.L. (2007): GGE biplot vs. AMMI analysis of genotype by environment data. - Crop Science 47: 643-655.

[35] Zobel, R.W., Wright, M.G., Gauch, H.G. (1988): Statistical analysis of a yield trial. Agron Journal 80: 388-393. 


\section{APPENDIX}

\begin{tabular}{|c|c|c|c|c|c|c|c|c|c|c|c|c|c|c|c|c|c|c|c|c|c|c|}
\hline \multirow[b]{2}{*}{ Genotype } & \multicolumn{11}{|c|}{ Thousand grain weight data (g) } & \multicolumn{11}{|c|}{ Test weight data (kg/hl) } \\
\hline & $\mathrm{E} 1$ & E2 & E3 & E4 & E5 & E6 & E7 & E8 & E9 & E10 & Mean & E1 & E2 & E3 & E4 & E5 & E6 & E7 & E8 & E9 & E10 & Mean \\
\hline G1 & 33.3 & 37.5 & 33.7 & 44.6 & 33.0 & 41.0 & 30.5 & 40.4 & 42.0 & 28.0 & 36.4 & 79.5 & 81.0 & 79.6 & 82.7 & 86.1 & 86.1 & 85.3 & 85.6 & 78 & 75.5 & 81.9 \\
\hline G2 & 33.4 & 39.4 & 32.4 & 45.3 & 34.0 & 41.3 & 33.3 & 40.4 & 42.5 & 31.8 & 37.4 & 71.4 & 77.9 & 74.2 & 77.7 & 82.1 & 82.1 & 81.3 & 83.6 & 72.6 & 70.1 & 77.3 \\
\hline G3 & 32.9 & 35.7 & 35.0 & 43.2 & 33.1 & 37.8 & 31.0 & 39.9 & 39.3 & 28.0 & 35.6 & 71.8 & 78.2 & 77.9 & 80.4 & 84.1 & 84.1 & 83.4 & 84.3 & 74.5 & 72 & 79.1 \\
\hline G4 & 30.7 & 39.4 & 29.5 & 43.4 & 30.3 & 36.3 & 29.8 & 36.6 & 34.5 & 25.5 & 33.6 & 76.2 & 80.0 & 77.5 & 81.5 & 84.7 & 84.7 & 81.2 & 84.6 & 75.2 & 72.7 & 79.8 \\
\hline G5 & 32.7 & 40.0 & 35.1 & 46.9 & 32.6 & 43.1 & 33.0 & 40.5 & 35.5 & 28.0 & 36.7 & 76.8 & 80.1 & 77.9 & 79.4 & 81.8 & 81.8 & 82.8 & 84.2 & 73.4 & 70.9 & 78.9 \\
\hline G6 & 33.3 & 37.5 & 34.8 & 46.9 & 37.3 & 38.6 & 32.0 & 39.5 & 38.8 & 29.3 & 36.8 & 79.2 & 81.8 & 80.6 & 82.9 & 85.6 & 85.6 & 85.8 & 85.3 & 80.2 & 77.7 & 82.5 \\
\hline G7 & 32.9 & 38.2 & 36.5 & 44.7 & 34.5 & 40.8 & 34.3 & 39.8 & 35.0 & 29.3 & 36.6 & 76.7 & 79.6 & 78.6 & 80.9 & 84.5 & 84.5 & 84.8 & 83.9 & 75.1 & 72.6 & 80.1 \\
\hline G8 & 29.9 & 35.7 & 32.6 & 46.8 & 31.3 & 39.9 & 32.0 & 40.0 & 34.0 & 25.5 & 34.8 & 71.5 & 78.4 & 77.8 & 80.9 & 84.2 & 84.2 & 83.7 & 84.0 & 73.7 & 71.2 & 78.9 \\
\hline G9 & 39.4 & 44.4 & 41.4 & 53.2 & 39.6 & 47.1 & 37.3 & 46.4 & 42.0 & 35.5 & 42.6 & 80.8 & 79.2 & 78.3 & 80.8 & 84.1 & 84.1 & 83.2 & 82.6 & 77.3 & 74.8 & 80.5 \\
\hline G10 & 40.4 & 43.2 & 37.9 & 50.8 & 43.8 & 50.6 & 37.8 & 46.0 & 46.8 & 38.0 & 43.5 & 77.8 & 79.9 & 79.4 & 81.6 & 84.3 & 84.3 & 82.8 & 83.8 & 78.4 & 75.9 & 80.8 \\
\hline G11 & 34.2 & 61.4 & 35.2 & 47.2 & 34.9 & 43.5 & 35.3 & 41.9 & 44.5 & 25.5 & 40.3 & 73.8 & 79.7 & 78.3 & 80.15 & 83.8 & 83.8 & 82.4 & 82.2 & 72.6 & 70.1 & 78.7 \\
\hline G12 & 33.1 & 41.3 & 37.7 & 46.6 & 34.1 & 40.1 & 32.3 & 38.8 & 35.3 & 24.3 & 36.3 & 73.2 & 79.1 & 77.3 & 80 & 83.3 & 83.3 & 83 & 80.9 & 70.6 & 68.1 & 77.9 \\
\hline G13 & 38.2 & 43.4 & 39.9 & 49.8 & 37.0 & 43.8 & 31.5 & 40.8 & 43.8 & 31.8 & 40.0 & 73.6 & 81.9 & 81.3 & 82.8 & 84.9 & 84.9 & 85.8 & 85.1 & 78.1 & 75.6 & 81.4 \\
\hline G14 & 39.9 & 41.9 & 42.0 & 49.5 & 42.3 & 45.5 & 33.8 & 42.1 & 44.0 & 31.8 & 41.3 & 79.8 & 81.2 & 81 & 83.7 & 84.8 & 84.8 & 84.4 & 83.9 & 77.9 & 75.4 & 81.7 \\
\hline G15 & 37.6 & 40.1 & 39.7 & 46.5 & 35.4 & 42.1 & 34.3 & 39.1 & 42.0 & 29.3 & 38.6 & 76.4 & 79.4 & 78.3 & 79.9 & 83.5 & 83.5 & 82.9 & 82.6 & 75.3 & 72.8 & 79.4 \\
\hline G16 & 32.1 & 33.8 & 33.0 & 43.6 & 29.3 & 35.0 & 28.5 & 36.3 & 35.8 & 24.3 & 33.1 & 75.9 & 80.9 & 81.6 & 82.9 & 86.3 & 86.3 & 85.5 & 86.7 & 79.7 & 77.2 & 82.3 \\
\hline G17 & 38.2 & 40.1 & 39.9 & 51.1 & 33.1 & 45.1 & 36.0 & 44.0 & 43.0 & 30.5 & 40.1 & 77.9 & 80.0 & 79.4 & 80.4 & 83.4 & 83.4 & 83.5 & 83.3 & 76.9 & 74.4 & 80.2 \\
\hline G18 & 30.7 & 39.4 & 33.4 & 41.2 & 27.9 & 33.5 & 31.3 & 38.6 & 37.0 & 26.8 & 34.0 & 75.0 & 79.7 & 78.6 & 80.7 & 81.9 & 81.9 & 83.2 & 83.8 & 75.2 & 72.7 & 79.3 \\
\hline G19 & 33.4 & 36.9 & 38.7 & 44.4 & 34.6 & 40.0 & 31.5 & 40.1 & 37.5 & 30.5 & 36.8 & 78.4 & 79.1 & 78.8 & 81.1 & 84.2 & 84.2 & 83.2 & 84.1 & 77.5 & 75 & 80.5 \\
\hline G20 & 36.6 & 40.7 & 33.7 & 46.7 & 35.1 & 40.0 & 32.0 & 40.6 & 30.0 & 33.0 & 36.8 & 75.4 & 79.2 & 77.7 & 80.8 & 83.9 & 83.9 & 82.5 & 82.2 & 78.5 & 76 & 80.0 \\
\hline G21 & 32.4 & 35.0 & 32.0 & 43.2 & 34.8 & 36.9 & 28.8 & 38.0 & 36.0 & 28.0 & 34.5 & 75.7 & 80.7 & 80.1 & 83.3 & 84.9 & 84.9 & 83.9 & 85.7 & 79.6 & 77.1 & 81.6 \\
\hline G22 & 28.5 & 33.8 & 30.9 & 40.2 & 28.0 & 35.4 & 28.8 & 34.5 & 33.3 & 24.3 & 31.8 & 77.5 & 81.1 & 79.9 & 82.2 & 86.4 & 86.4 & 84.8 & 85.2 & 77.9 & 75.4 & 81.7 \\
\hline G23 & 39.7 & 40.7 & 40.6 & 49.3 & 40.5 & 45.5 & 35.5 & 42.5 & 40.3 & 30.5 & 40.5 & 75.0 & 81.1 & 81.2 & 81.6 & 84.7 & 84.7 & 85.3 & 85.0 & 79 & 76.5 & 81.4 \\
\hline G24 & 32.2 & 34.4 & 31.0 & 39.4 & 32.0 & 36.5 & 28.0 & 34.3 & 34.5 & 26.8 & 32.9 & 78.9 & 80.3 & 79.1 & 81.3 & 84.7 & 84.7 & 85 & 85.5 & 78.2 & 75.7 & 81.3 \\
\hline $\mathrm{G} 25$ & 33.5 & 37.5 & 33.3 & 43.2 & 32.6 & 37.0 & 32.5 & 39.5 & 42.0 & 26.8 & 35.8 & 78.8 & 80.8 & 79.1 & 82.5 & 85.6 & 85.6 & 85.1 & 82.0 & 78.8 & 76.3 & 81.4 \\
\hline Mean & 34.3 & 39.6 & 35.6 & 45.9 & 34.4 & 40.7 & 32.4 & 40.0 & 38.8 & 28.9 & 37.1 & 76.3 & 80.0 & 78.9 & 81.3 & 84.3 & 84.3 & 83.8 & 84.0 & 76.6 & 74.1 & 80.3 \\
\hline
\end{tabular}

APPLIED ECOLOGY AND ENVIRONMENTAL RESEARCH 14(4): 159-176.

http://www.aloki.hu • ISSN 15891623 (Print) • ISSN 17850037 (Online)

DOI: http://dx.doi.org/10.15666/aeer/1404_159176

(c) 2016, ALÖKI Kft., Budapest, Hungary 


\begin{tabular}{|c|c|c|c|c|c|c|c|c|c|c|c|c|c|c|c|c|c|c|c|c|c|c|}
\hline \multirow[b]{2}{*}{ Genotype } & \multicolumn{11}{|c|}{ Heading days (days from January 1) } & \multicolumn{11}{|c|}{ Plant height $(\mathrm{cm})$} \\
\hline & E1 & E2 & E3 & E4 & E5 & E6 & E7 & E8 & E9 & E10 & Mean & E1 & E2 & E3 & $\mathrm{E} 4$ & E5 & E6 & E7 & E8 & E9 & E10 & Mean \\
\hline G1 & 123 & 124 & 126 & 108 & 128 & 123 & 130 & 122 & 118 & 124 & 123 & 105 & 95 & 105 & 100 & 105 & 105 & 75 & 95 & 90 & 75 & 95 \\
\hline G2 & 122 & 121 & 124 & 107 & 122 & 121 & 125 & 113 & 114 & 122 & 119 & 95 & 90 & 105 & 100 & 95 & 95 & 75 & 95 & 90 & 75 & 92 \\
\hline G3 & 123 & 123 & 125 & 111 & 123 & 122 & 128 & 115 & 116 & 123 & 121 & 108 & 100 & 108 & 115 & 110 & 115 & 80 & 100 & 95 & 85 & 102 \\
\hline G4 & 124 & 124 & 120 & 111 & 128 & 123 & 130 & 118 & 118 & 123 & 122 & 100 & 95 & 100 & 105 & 100 & 105 & 75 & 90 & 90 & 75 & 94 \\
\hline G5 & 130 & 127 & 131 & 112 & 126 & 123 & 132 & 120 & 117 & 124 & 124 & 120 & 105 & 120 & 115 & 120 & 125 & 80 & 105 & 105 & 95 & 109 \\
\hline G6 & 123 & 119 & 124 & 105 & 121 & 120 & 125 & 115 & 113 & 128 & 119 & 110 & 95 & 113 & 110 & 110 & 110 & 90 & 95 & 100 & 80 & 101 \\
\hline G7 & 125 & 126 & 130 & 109 & 123 & 126 & 130 & 116 & 116 & 123 & 122 & 110 & 95 & 113 & 110 & 105 & 110 & 95 & 95 & 100 & 85 & 102 \\
\hline G8 & 126 & 128 & 131 & 112 & 126 & 127 & 131 & 119 & 120 & 124 & 124 & 110 & 95 & 98 & 115 & 115 & 110 & 80 & 90 & 100 & 95 & 101 \\
\hline G9 & 120 & 115 & 123 & 104 & 120 & 120 & 123 & 113 & 113 & 121 & 117 & 105 & 85 & 115 & 100 & 105 & 105 & 75 & 95 & 100 & 90 & 98 \\
\hline G10 & 131 & 132 & 133 & 115 & 130 & 126 & 132 & 121 & 122 & 125 & 127 & 115 & 100 & 115 & 120 & 110 & 110 & 70 & 90 & 90 & 100 & 102 \\
\hline G11 & 130 & 128 & 131 & 114 & 130 & 126 & 132 & 122 & 119 & 124 & 126 & 110 & 100 & 115 & 110 & 110 & 110 & 85 & 100 & 100 & 90 & 103 \\
\hline G12 & 130 & 127 & 131 & 113 & 129 & 127 & 132 & 122 & 118 & 124 & 125 & 110 & 95 & 113 & 120 & 115 & 110 & 80 & 95 & 100 & 95 & 103 \\
\hline G13 & 120 & 114 & 122 & 103 & 120 & 118 & 123 & 112 & 113 & 118 & 116 & 110 & 95 & 115 & 115 & 110 & 110 & 80 & 105 & 90 & 90 & 102 \\
\hline G14 & 120 & 113 & 122 & 104 & 120 & 119 & 123 & 112 & 113 & 120 & 117 & 100 & 85 & 103 & 110 & 105 & 95 & 80 & 95 & 90 & 85 & 95 \\
\hline G15 & 134 & 132 & 135 & 114 & 130 & 129 & 134 & 121 & 121 & 125 & 128 & 113 & 95 & 110 & 105 & 115 & 120 & 75 & 110 & 105 & 105 & 105 \\
\hline G16 & 123 & 125 & 125 & 109 & 122 & 122 & 126 & 113 & 115 & 122 & 120 & 95 & 95 & 108 & 105 & 100 & 100 & 70 & 90 & 85 & 85 & 93 \\
\hline G17 & 125 & 126 & 129 & 111 & 128 & 123 & 130 & 117 & 119 & 122 & 123 & 118 & 105 & 125 & 110 & 110 & 115 & 75 & 95 & 100 & 95 & 105 \\
\hline G18 & 126 & 128 & 129 & 112 & 127 & 123 & 131 & 118 & 119 & 124 & 124 & 105 & 85 & 115 & 110 & 115 & 105 & 75 & 95 & 90 & 95 & 99 \\
\hline G19 & 131 & 126 & 133 & 115 & 129 & 128 & 133 & 120 & 122 & 125 & 126 & 110 & 105 & 115 & 100 & 115 & 115 & 75 & 95 & 95 & 95 & 102 \\
\hline G20 & 127 & 127 & 130 & 114 & 129 & 128 & 130 & 116 & 122 & 124 & 125 & 85 & 80 & 90 & 95 & 75 & 70 & 60 & 75 & 75 & 75 & 78 \\
\hline G21 & 123 & 123 & 124 & 109 & 123 & 123 & 126 & 114 & 115 & 122 & 120 & 90 & 90 & 103 & 100 & 85 & 85 & 60 & 80 & 80 & 80 & 85 \\
\hline G22 & 124 & 124 & 124 & 110 & 125 & 124 & 129 & 115 & 117 & 121 & 121 & 103 & 100 & 113 & 105 & 115 & 115 & 75 & 95 & 95 & 90 & 101 \\
\hline $\mathrm{G} 23$ & 122 & 123 & 123 & 108 & 121 & 122 & 127 & 114 & 114 & 121 & 120 & 103 & 100 & 110 & 100 & 110 & 110 & 65 & 100 & 100 & 90 & 99 \\
\hline G24 & 120 & 124 & 123 & 107 & 122 & 122 & 128 & 114 & 114 & 122 & 120 & 93 & 80 & 103 & 100 & 90 & 90 & 70 & 90 & 85 & 80 & 88 \\
\hline $\mathrm{G} 25$ & 124 & 127 & 129 & 111 & 125 & 122 & 130 & 116 & 118 & 123 & 123 & 108 & 95 & 113 & 110 & 110 & 105 & 75 & 100 & 95 & 90 & 100 \\
\hline Mean & 125 & 124 & 127 & 110 & 125 & 123 & 129 & 117 & 117 & 123 & 122 & 105 & 94 & 110 & 107 & 106 & 106 & 76 & 95 & 94 & 88 & 98 \\
\hline
\end{tabular}




\begin{tabular}{|c|c|c|c|c|c|c|c|c|c|c|c|c|c|c|c|c|c|c|c|c|c|c|}
\hline \multirow[b]{2}{*}{ Genotype } & \multicolumn{11}{|c|}{ Mini Sds Sedimentation data(ml) } & \multicolumn{11}{|c|}{ Protein content data (\%) } \\
\hline & E1 & $\mathrm{E} 2$ & E3 & $\mathrm{E} 4$ & E5 & E6 & E7 & E8 & E9 & E10 & Mean & E1 & $\mathrm{E} 2$ & E3 & $\mathrm{E} 4$ & E5 & E6 & E7 & E8 & E9 & E10 & Mean \\
\hline G1 & 11.0 & 15.8 & 10.0 & 8.5 & 13.6 & 9.7 & 18.0 & 11.5 & 14.0 & 13.0 & 12.5 & 11.1 & 11.9 & 10.4 & 10.3 & 10.9 & 10.4 & 13.1 & 12.2 & 12.6 & 12.7 & 11.6 \\
\hline G2 & 11.5 & 11.2 & 12.0 & 8.5 & 7.3 & 12.0 & 16.0 & 13.5 & 10.5 & 13.5 & 11.6 & 12.1 & 11.2 & 9.3 & 8.8 & 11.7 & 11.3 & 12.1 & 10.6 & 11.0 & 12.3 & 11.0 \\
\hline G3 & 13.0 & 15.0 & 12.0 & 9.0 & 12.5 & 13.6 & 23.0 & 14.5 & 13.0 & 16.5 & 14.2 & 11.5 & 11.4 & 9.0 & 9.4 & 12.2 & 11.8 & 13.3 & 12.3 & 12.7 & 12.9 & 11.7 \\
\hline G4 & 11.0 & 15.1 & 12.0 & 8.5 & 12.3 & 10.9 & 20.0 & 13.0 & 14.5 & 13.5 & 13.1 & 12.2 & 10.6 & 9.5 & 9.2 & 11.2 & 10.8 & 12.7 & 11.5 & 11.9 & 13.0 & 11.2 \\
\hline G5 & 10.0 & 11.9 & 9.5 & 8.5 & 10.9 & 12.8 & 15.0 & 13.0 & 9.5 & 12.0 & 11.3 & 11.6 & 12.5 & 8.3 & 8.6 & 11.8 & 11.4 & 12.4 & 11.5 & 11.9 & 11.6 & 11.2 \\
\hline G6 & 10.0 & 16.7 & 11.0 & 9.0 & 17.1 & 14.6 & 23.0 & 14.5 & 11.0 & 14.5 & 14.1 & 11.7 & 12.3 & 10.4 & 11.7 & 12.1 & 11.7 & 14.1 & 12.7 & 13.0 & 12.5 & 12.2 \\
\hline G7 & 13.0 & 18.0 & 12.0 & 10.5 & 17.6 & 16.2 & 22.0 & 15.0 & 14.0 & 13.5 & 15.2 & 11.9 & 13.1 & 11.5 & 11.1 & 12.6 & 12.2 & 13.0 & 12.4 & 12.9 & 12.9 & 12.4 \\
\hline G8 & 12.0 & 11.6 & 10.0 & 9.0 & 14.5 & 8.6 & 19.0 & 11.5 & 11.0 & 12.5 & 12.0 & 11.7 & 12.4 & 11.5 & 10.7 & 11.1 & 10.7 & 13.3 & 11.2 & 11.6 & 13.2 & 11.7 \\
\hline G9 & 12.0 & 11.3 & 10.5 & 8.0 & 13.4 & 8.6 & 19.0 & 11.5 & 10.0 & 14.5 & & 11.1 & 12.6 & 10.5 & 10.9 & 11.2 & 10.7 & 13.3 & 10.9 & 11.9 & 11.6 & 11.5 \\
\hline G10 & 11.0 & 14.7 & 9.0 & 7.5 & 13.6 & 10.6 & 18.0 & & & 11.5 & & & & 10.5 & 11.3 & & 11.2 & 13.4 & 12.3 & 12.8 & 12.3 & 12.0 \\
\hline G11 & 13.0 & 14.8 & 12.0 & 11.0 & 15.8 & 11.0 & 23.0 & 12.5 & 15.0 & 15.5 & & 12.1 & 13.6 & 10.4 & 11.0 & 11.9 & 10.8 & 13.4 & 12.7 & 13.0 & 13.0 & 12.2 \\
\hline G12 & 13.0 & 18.7 & 11.0 & 11.5 & 14.9 & 12.9 & 22.0 & 13.5 & 15.5 & 16.5 & 14.9 & 11.7 & 10.1 & 11.2 & 10.1 & 11.8 & 11.2 & 13.4 & 12.8 & 13.2 & 13.5 & 11.9 \\
\hline G13 & 11.5 & 13.5 & 10.0 & 10.5 & 17.3 & 12.7 & 21.0 & 13.5 & 6.0 & 14.0 & 13.0 & 11.1 & 10.3 & 11.0 & 10.1 & 12.0 & 11.6 & 14.2 & 11.9 & 7.3 & 14.1 & 11.4 \\
\hline G14 & 13.0 & 22.8 & 11.5 & 11.0 & 19.1 & 18.8 & 23.0 & 15.0 & 15.5 & 14.5 & 16.4 & 11.3 & 12.8 & 11.9 & 9.7 & 13.2 & 12.9 & 14.5 & 15.1 & 15.3 & 14.3 & 13.1 \\
\hline G15 & 9.0 & 17.1 & 8.5 & 7.5 & 19.3 & 12.6 & 18.0 & 10.5 & 6.5 & 13.5 & 12.2 & 12.0 & 11.6 & 11.2 & 9.3 & 12.0 & 11.4 & 14.4 & 12.4 & 12.9 & 13.2 & 12.0 \\
\hline G16 & 13.0 & 17.9 & 12.0 & 11.0 & 14.6 & 10.5 & 25.0 & 16.5 & 18.5 & 16.5 & 15.5 & 12.7 & 12.6 & 12.5 & 10.6 & 11.7 & 11.2 & 13.7 & 12.5 & 12.9 & 14.6 & 12.5 \\
\hline G17 & 11.0 & 13.9 & 7.5 & 8.5 & 16.8 & 8.5 & 18.0 & 11.5 & 8.0 & 12.5 & 11.6 & 12.8 & 12.5 & 10.4 & 9.8 & 11.0 & 10.6 & 13.9 & 11.9 & 12.4 & 11.6 & 11.7 \\
\hline G18 & 12.0 & 10.2 & 10.0 & 8.5 & 13.4 & 10.5 & 18.0 & 12.0 & 7.0 & 15.5 & 11.7 & 10.9 & 12.3 & 9.7 & 9.9 & 11.7 & 11.2 & 13.1 & 11.3 & 11.8 & 14.1 & 11.6 \\
\hline G19 & 10.0 & 10.3 & 7.5 & 8.0 & 9.3 & 8.5 & 17.0 & 11.0 & 9.0 & 12.5 & 10.3 & 11.1 & 11.5 & 11.1 & 9.7 & 10.8 & 10.3 & 12.3 & 10.6 & 11.0 & 11.4 & 11.0 \\
\hline G20 & 11.0 & 12.9 & 10.0 & 10.0 & 15.5 & 13.7 & 21.0 & 14.0 & 15.0 & 12.5 & 13.6 & 10.8 & 13.1 & 11.3 & 11.4 & 12.6 & 12.0 & 13.9 & 11.6 & 12.0 & 11.7 & 12.0 \\
\hline G21 & 11.5 & 16.6 & 9.0 & 8.0 & 16.3 & 13.1 & 21.0 & 9.5 & 11.5 & 11.0 & 12.8 & 10.7 & 12.5 & 10.3 & 10.8 & 12.0 & 11.5 & 13.7 & 12.5 & 12.9 & 12.7 & 12.0 \\
\hline G22 & 14.0 & 18.6 & 12.0 & 11.5 & 16.1 & 15.7 & 23.0 & 16.0 & 17.5 & 14.5 & 15.9 & 12.8 & 11.4 & 11.9 & 11.3 & 12.8 & 12.3 & 14.0 & 13.3 & 13.6 & 13.7 & 12.7 \\
\hline G23 & 13.0 & 16.9 & 10.0 & 11.0 & 17.0 & 13.3 & 24.0 & 15.0 & 15.0 & 14.5 & 15.0 & 11.1 & 12.6 & 10.7 & 12.3 & 12.3 & 11.8 & 14.2 & 13.5 & 13.8 & 13.8 & 12.6 \\
\hline $\mathrm{G} 24$ & 7.0 & 17.5 & 6.0 & 6.0 & 14.8 & 9.1 & 15.0 & 10.5 & 9.5 & 8.5 & 10.4 & 10.3 & 11.6 & 10.1 & 11.5 & 11.1 & 10.7 & 13.5 & 12.6 & 13.0 & 11.5 & 11.6 \\
\hline $\mathrm{G} 25$ & 10.0 & 15.5 & 9.0 & 10.0 & 15.4 & 11.0 & 19.0 & 13.0 & 11.5 & 13.0 & 12.7 & 11.9 & 11.7 & 10.7 & 10.8 & 11.3 & 10.8 & 13.4 & 12.4 & 12.9 & 11.6 & 11.8 \\
\hline Mean & 11.5 & 15.1 & 10.2 & 9.2 & 14.7 & 12.0 & 20.0 & 12.9 & 12.0 & 13.6 & 13.1 & 11.6 & 12.0 & 10.6 & 10.4 & 11.8 & 11.3 & 13.4 & 12.2 & 12.4 & 12.8 & 11.9 \\
\hline
\end{tabular}

